\title{
Impronta Genómica y Desarrollo Embrionario
}

\author{
Genomic Imprinting and Embryonic Development
}

*,*** German Reig \& *,** Miguel L. Concha

\begin{abstract}
REIG, G \& CONCHA, M. Impronta genómica y desarrollo embrionario. Int. J. Morphol., 30(4):1453-1457, 2012.
RESUMEN: En los organismos diploides, cada gen autosómico está representado por dos copias, o alelos, heredados de cada progenitor al momento de la fecundación. Para la gran mayoría de los genes la expresión ocurre desde ambos alelos de manera simultánea. Sin embargo, un número reducido de genes (menos del 1\%) es afectado por un proceso de impronta genómica. Este proceso determina que la expresión del gen sea dependiente del origen parental, es decir, se comporte de manera distinta si su origen es materno o paterno. La metilación del ADN es una de las modificaciones epigenéticas mejor estudiadas y su participación resulta esencial durante el establecimiento de la impronta genómica. Si bien los patrones de metilación a nivel genómico son estables y heredables, existen al menos dos períodos del desarrollo embrionario de mamíferos durante los cuales los patrones de metilación globales son borrados y reestablecidos. Estos dos períodos del desarrollo coinciden con el borrado y establecimiento de la impronta genómica específica de cada individuo. Desde el punto de vista funcional, la mayoría de los genes sometidos a impronta cumplen roles en el control del crecimiento y desarrollo embrionario y placentario. Alteraciones en el patrón de expresión de ellos han sido relacionados a patologías tales como el Síndrome de Algelman y el Síndrome de Prader-Willi, entre otros.
\end{abstract}

PALABRAS CLAVE: Impronta genómica; Metilación del ADN; Epigenética; Desarrollo embrionario

\section{INTRODUCCIÓN}

Epigenética. La epigenética es el proceso mediante el cual se producen cambios químicos heredables en los genes, los que sin modificar sus secuencias nucleotídicas son capaces de alterar su expresión fenotípica (Bird, 2007). Estos cambios se mantienen durante las sucesivas divisiones celulares $\mathrm{y}$, por tanto, una vez que se establecen son transmitidos a las células descendientes (Bird). Los mecanismos epigenéticos participan de manera central en los procesos de impronta genómica, la inactivación de uno de los cromosomas X en las hembras de los mamíferos y el proceso de diferenciación celular (Bird; Reik et al., 2001).

Las modificaciones epigenéticas constituyen un mecanismo pre-transcripcional de regulación de la expresión génica que cambian la estructura de la cromatina por la acción conjunta y sinérgica de tres procesos: variaciones en los patrones de condensación de la cromatina, grado de metilación del ADN y modificaciones covalentes de las histonas (Sha, 2008).

\section{IMPRONTA GENÓMICA DURANTE EL DESA- RROLLO EMBRIONARIO. El desarrollo normal de los}

mamíferos requiere una expresión apropiada de los genes derivados tanto del genoma materno como paterno. La mayoría de los genes son expresados independientemente de su origen parental. Sin embargo, un número reducido de ellos (aproximadamente 100 genes) son regulados y transcritos en una manera mono-alélica. Para estos genes, denominados genes imprintados (marcados), su patrón de expresión y regulación es dependiente de su origen parental, es decir, se comporta de una manera distinta si su origen es paterno o materno. Para estos genes existen mecanismos específicos de control que aseguran su correcta expresión (Colmes, \& Soloway, 2006; Ferguson-Smith 2011; Sha, 2008).

\section{I.a. Metilación del ADN y establecimiento de la impron-} ta genómica. La metilación del ADN es una de las modificaciones epigenéticas mejor estudiadas y juega un papel fundamental en el establecimiento de la impronta genómica ( $\mathrm{Li}$, 1993; Reik et al., 2001). En mamíferos, el proceso de metilación ocurre predominantemente en las bases nitrogenadas de citosina. Si bien los patrones de metilación a nivel genómico son estables y heredables, existen al menos dos períodos del desarrollo embrionario en los que el patrón de metilación global es borrado y re-establecido:

\footnotetext{
* Laboratorio de Estudios Ontogénicos, Programa de Anatomía y Biología del Desarrollo, Facultad de Medicina, Universidad de Chile.

*** Instituto de Neurociencias Biomédicas, Universidad de Chile, Santiago, Chile.
} 
durante la generación de las células germinales (Fig. 1A), y en el período de pre-implantación embrionario (Fig. 1B). De manera coincidente, la impronta genómica se establece en estos dos períodos de reprogramación global del patrón de metilación del ADN (Reik et al., 2001; Weaver et al., 2009).

El genoma de las células germinales masculinas y femeninas maduras está altamente metilado (Fig. 1B), aunque sufre modificaciones importantes poco después de la fecundación. El genoma paterno se demetila de manera activa y alcanza a completarse antes del comienzo de la replicación del ADN (curva celeste en Fig. 1B).

A

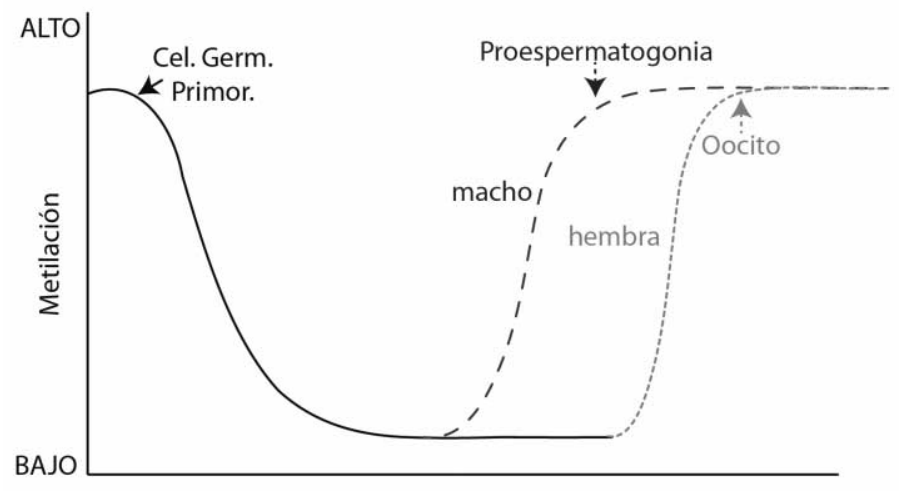

Tiempo de desarrollo

B

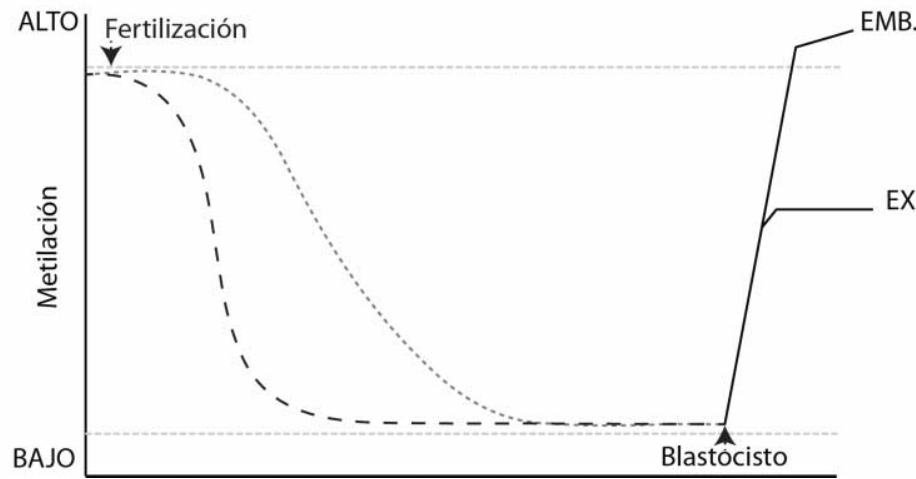

Fig. 1. Patrón de metilación del ADN durante la generación de las células germinales y el período de pre-implantación embrionaria de ratón.

(A) Patrón de metilación del ADN durante la generación de las células germinales. El patrón de metilación es borrado en el momento en que las células germinales ingresan a la gónada. Luego de algunos días, el patrón de metilación es reestablecido de manera sexo-específica: la línea germinal masculina alcanza su estado de metilación en el estadio de proespermatogonia, mientras que la línea germinal femenina lo completa después del nacimiento.

(B) Metilación del ADN durante la fertilización. Poco después de la fertilización los genomas paternos (curva celeste) y maternos (curva roja) son demetilados, aunque algunos genes imprintados permanecen con su estado de metilación (línea punteada superior). Durante el desarrollo posterior, los patrones de metilación son reestablecidos en tejidos embrionarios (EM) y extra-embrionarios (EX). Modificado de Reik et al., 2001.
A pesar de estos cambios globales, algunos genes imprintados, así como secuencias repetitivas, mantienen su estado de metilación (línea punteada superior), lo que resulta esencial para el desarrollo embrionario posterior. El genoma materno en tanto, sufre una demetilación más lenta por un mecanismo pasivo que depende la replicación del ADN (curva roja en Fig. 1B). Durante el desarrollo posterior los patrones de metilación son nuevamente establecidos tanto en tejidos embrionarios como extraembrionarios.

El segundo período de reprogramación del patrón de metilación se establece durante la generación de las células germinales. En este caso, el patrón de demetilación global incluye a los genes imprintados y se completa entre los días embrionarios E13-E14 en el ratón, momento en el cual las células germinales primordiales ingresan a la gónada. Una vez que esto ocurre, las células germinales primordiales masculinas y femeninas entran en arresto mitótico y meiótico, respectivamente. La remetilación ocurre algunos días mas tarde y se completa de manera diferencial en ambos sexos. La línea germinal masculina alcanza su estado "metilado" durante el estadio de proespermatogonia (E15-E16), mientras que la línea germinal femenina lo completa luego del nacimiento, durante el crecimiento del ovocito. De esta manera quedan establecidos nuevamente los patrones de expresión de los genes imprintados, completando el ciclo (Fig. 2).

I.b. Contribución de los genomas parentales al embrión. Durante la década de los 80 , los científicos evaluaron la contribución de los genomas parentales al desarrollo embrionario mediante la creación de diploides ginogenéticos y androgenéticos, constituidos ya sea de dos genomas de origen materno o paterno, respectivamente. Los diploides ginogenéticos (con dos copias del genoma materno) mostraron un pobre desarrollo de las membranas extra-embrionarias (saco vitelino y trofoblasto), aunque los embriones inicialmente eran relativamente normales (Fig. 3). En tanto, los diploides androgenéticos (con dos copias del genoma paterno) tenían un desarrollo normal de las membranas extra-embrionarias, aunque las estructuras embrionarias eran anormales (Fig. 3). Ambas condiciones eran letales.

En humanos, ocasionalmente y en forma espontánea, se producen embriones que son parcialmente ginogenéticos o androgenéticos para un 


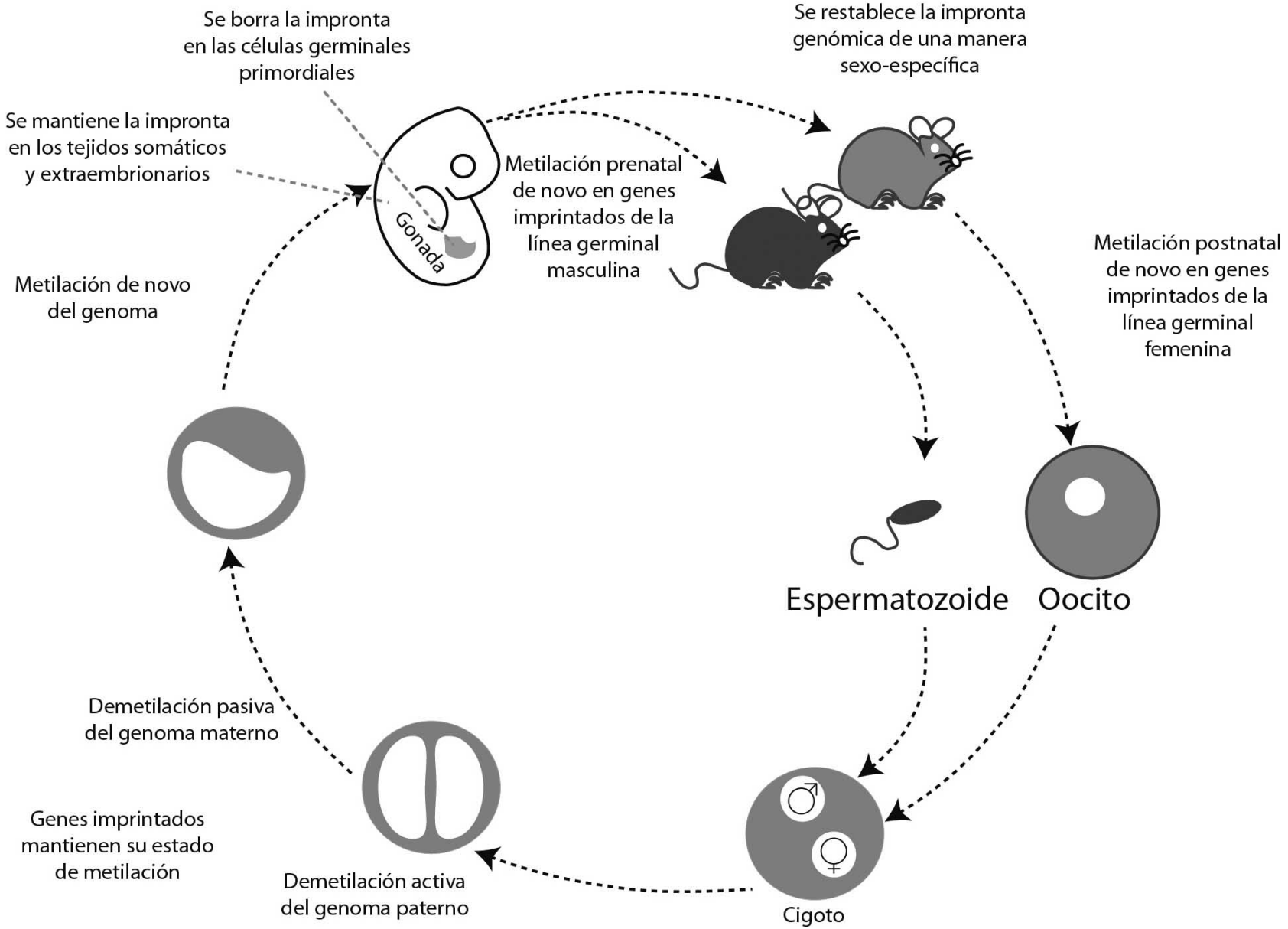

Fig. 2. Ciclo de establecimiento de la impronta durante el desarrollo del ratón. Detalles de la figura son entregados en el texto. Modificado de Reik et al., 2001.

cromosoma en particular. Las disomias uniparentales son alteraciones cromosómicas caracterizadas porque en un genoma las dos copias de un determinado cromosoma derivan exclusivamente de uno de los progenitores. Estas disomías uniparentales surgen cuando se fusionan gametos parentales que experimentaron no disyunción meiótica durante su generación. Individuos que son disómicos para el par de cromosomas 15, por ejemplo, presentan un fenotipo anómalo y la anomalía es distinta según si ambos cromosomas 15 son de origen paterno o materno. Esta se denomina Síndrome de Angelman y Sindrome de PraderWilli, respectivamente. Sin embargo, las disomías uniparentales son sólo la causa del 3 al 5\% del Síndrome de Angelman y del 25-30\% del Síndrome de Prader-Willi. La causa mas frecuente de estos síndromes (70-75\% de los casos) corresponden a deleciones de un pequeño sector del cromosoma 15 (15q.11.13) que cuando afecta al cromosoma 15 de origen materno origina el Síndrome de
Angelman y cuando afecta al cromosoma 15 de origen paterno origina el Síndrome de Prader-Willi (Butler, 2009).

\section{METILACION Y REGULACION DE LOS GENES} igf2/H19. Numerosos estudios sugieren la contribución de diversas señales regulatorias al mecanismo de impronta genómica. Las mismas están ubicadas dentro o en la proximidad de los genes imprintados (Sha, 2008). Las regiones o dominios de metilación diferencial (DMR) usualmente funcionan como sitios de metilación del ADN dependiente del origen parental (Colmes \& Soloway, 2006). Ciertos DMR pueden también funcionar como "aisladores" (insulators), los cuales cumplen con dos características: a) cuando se ubican entre un aumentador (enhancer) y un promotor, son capaces de prevenir la activación del promotor; y b) cuando se ubican río arriba o debajo de un transgén, son capaces de proteger al mismo de los efectos posicionales. Uno de los 

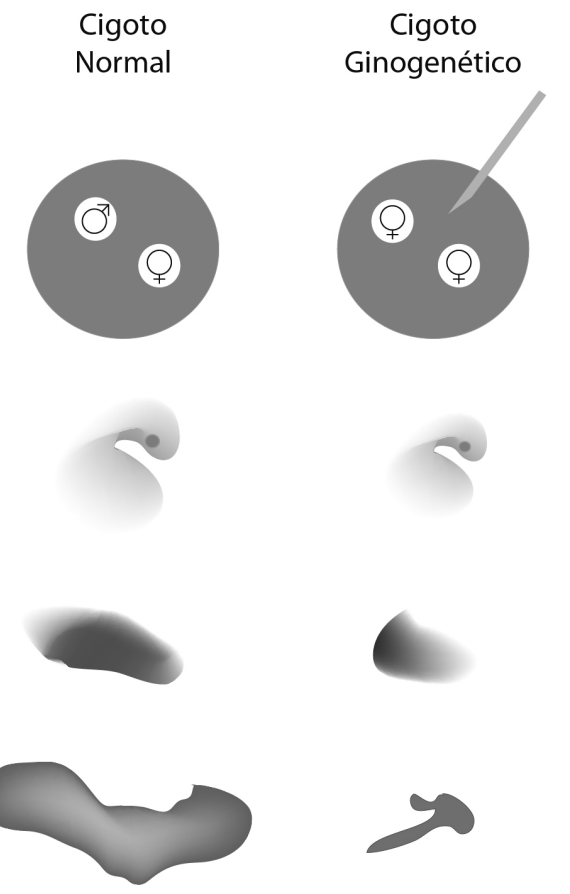

Saco

Vitelino
Trofoblasto
Tejido

Embrionario
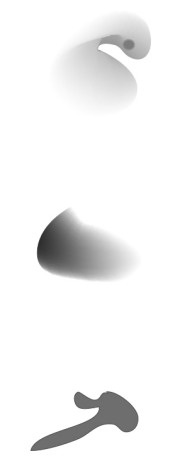

Cigoto Androgenético
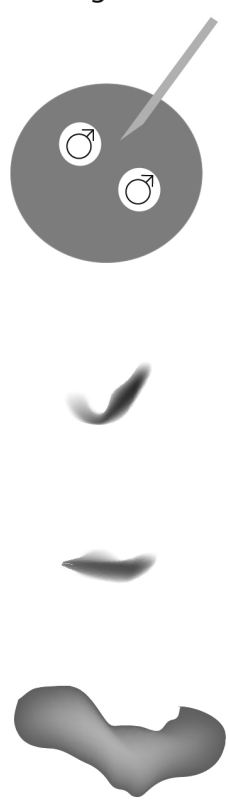

Fig. 3. Contribución parental al desarrollo embrionario. Los genomas materno y paterno contribuyen de manera complementaria al desarrollo embrionario. Cuando se encuentra presente una copia del genoma materno y una del genoma del paterno, el cigoto presenta un desarrollo normal tanto de los tejidos embrionarios como extra-embrionarios, los que incluyen el trofoblasto y saco vitelino. La ausencia de una copia del genoma paterno, denominado cigoto ginogenético genera alteraciones en el desarrollo de las membranas extra-embrionarias. Por otro lado, ante la ausencia de una copia del genoma materno, denominado cigoto androgenético, el desarrollo de los tejidos embrionarios se ve disminuído.
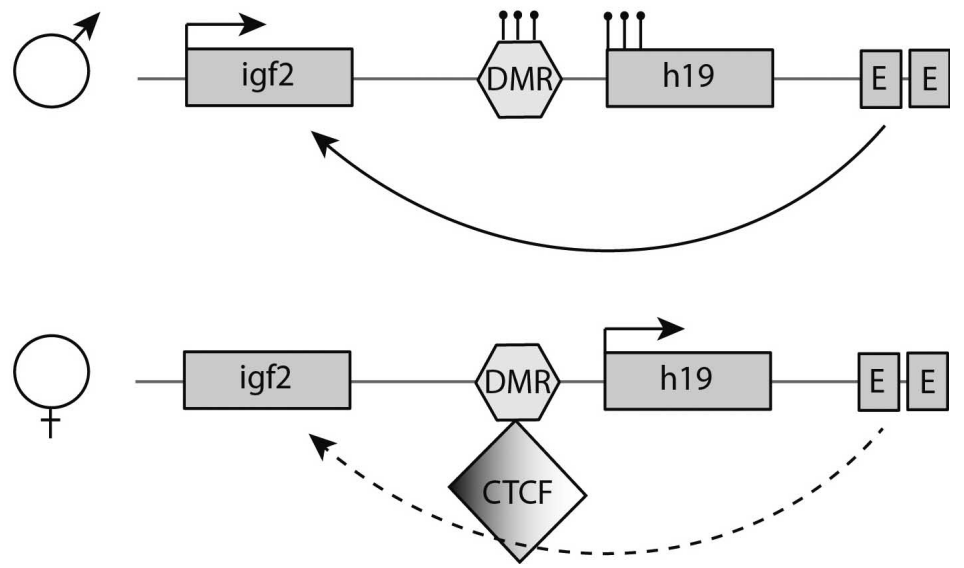

Fig. 4. Mecanismo de regulación de los genes Igf2 y H19. El genoma paterno expresa activamente el gen IGF2 por la acción de elementos aumentadores o enhancers (E) presentes río abajo del mismo. En tanto el gen H19, no es expresado debido a la metilación sobre la región de metilación diferencial (DMR) y en el promotor del gen. En tanto, en el genoma materno la ausencia de metilación en laregión DMR provoca el reclutamiento de proteínas del tipo CTCF, las cuales bloquean la actividad de los aumentadores sobre el gen Igf2. En consecuencia la expresión del gen Igf2 se ve interrumpida y se favorece la actividad de los aumentadores sobre la expresión del gen H19. mejores ejemplos de regulación de la expresión génica mediado por DMR es el que afecta a los genes imprintados igf2/H19. El gen igf2 codifica para un factor de crecimiento fetal, mientras que H19 es un ARN no codificante. Los dos genes están separados sólo por 90 kilobases, y son regulados por impronta genómica. En el cromosoma paterno la expresión de H19 está reprimida como resultado de la fuerte metilación que ocurre sobre las DMR. Esta metilación sobre la DMR a su vez induce cambios epigenéticos sobre el promotor de H19, que dan como resultado un silenciamiento de su expresión (Fig. 4). En el cromosoma materno, la ausencia de metilación sobre la DMR favorece dos eventos: a) el reclutamiento de la proteína CTCF, la cual bloquea la actividad de los aumentadores (E) sobre el gen Igf2, lo que resulta en la inhibición de su expresión; y b) la expresión de H19 (Fig. 4). Así, los genomas materno y paterno complementan la expresión de sus genes.

\section{ALTERACIONES DE LA IM- PRONTA GENÓMICA: SINDRO- ME DE PRADER-WILLI Y} ANGelman. El Síndrome de Prader-Willi (SPW) y el Síndrome de Angelman (SA) fueron los primeros ejemplos de impronta genómica en seres humanos. El SPW es una condición genética compleja que se caracteriza por retardo mental, hipotonía infantil, corta estatura, hipogonadismo, siendo la obesidad el problema más significativo (Butler, 2009). En 1983, Butler y Palmer fueron los primeros en demostrar la relación entre la aparición del SPW con una deleción de un fragmento del cromosoma 15 que deriva del padre (Butler \& Palmer 1983). Cerca de un $70 \%$ de los sujetos que padecen el SPW poseen una deleción del segmento15q11-q13, un $25 \%$ un disomia unparental materna y sólo un $5 \%$ de los casos corresponde a alteraciones en las regiones reguladoras próximas de los genes involucrados. A 
diferencia del SPW, el cual involucra diversos genes candidatos, el SA es causado por la pérdida de un gen imprintado, ube3a, siendo expresado sólo el alelo materno. Este gen codifica para una Ubiquitin Ligasa E3 cuya funcionalidad parece crítica durante el desarrollo de las ramas terminales sinápticas de las dendritas en ciertas regiones del cerebro relacionadas con el aprendizaje y la memoria tales como el hipocampo y cerebelo (Lu et al., 2009; Wilkinson, 2007).

\section{CONCLUSIONES}

En los organismos diploides, la expresión de la gran mayoría de los genes ocurre desde ambos alelos de manera simultánea. Sin embargo, un número reducido de ellos es afectado por un proceso de impronta genómica, y por lo tanto, su expresión depende del origen parental. Los mecanismos de regulación que aseguran este patrón de expresión son epigenéticos, entre los que se incluyen modificaciones covalentes de histonas, y metilación del ADN. A pesar de los avances en el entendimiento de los mecanismos celulares que regulan la impronta, mucho permanece aún por ser descubierto. De manera interesante, el establecimiento de la impronta puede ser visto como un mecanismo dinámico que puede ser regulado, incluso de manera tejido específico (Weinstein, 2001). En cualquier caso, alteraciones en el patrón de impronta, y en consecuencia, del patrón de expresión génica resultan en patologías que incluyen al Síndrome de Angelman y al Síndrome de Prader-Willi, entre otros.

REIG, G. \& CONCHA, M.L. Genomic imprinting and embryonic development. Int. J. Morphol., 30(4):1453-1457, 2012.

SUMMARY: In diploid organisms, autosomal genes are composed of two copies, or alleles, inherited from both parents at fertilization. For the vast majority of autosomal genes, expression occurs from both alleles simultaneously. However, a small proportion $(<1 \%)$ of genes are imprinted, meaning that their expression depends on the parental origin . DNA methylation is one of the most known epigenetic modifications and its function is critical for the establishment of imprinting. The global pattern of genomic methylation is stable and inheritable, however, it is erased and re-established in a sex-depended manner at two critical periods of embryonic development. Functionally, the majority of imprinted genes play roles in the control of embryonic and placental growth and development. Alterations in imprinted genes have been correlated with several pathologies including the Angelman and Prader-Willi syndromes.

KEY WORDS: Genomic imprinting; DNA methylation; Epigenetics; Embryonic development.

\section{REFERENCIAS BIBLIOGRÁFICAS}

Bird, A. Perceptions of epigenetics. Nature, 447(7143):396-8, 2007.

Butler M.G.; Palmer C.G. Parental origin of chromosome 15 deletion in Prader-Willi syndrome. Lancet, 1(8336):1285-6, 1983.

Butler, M. G. Genomic imprinting disorders in humans: a minireview. J. Assist. Reprod. Genet., 26:477-86, 2009.

Colmes, R.; Soloway, P.D. Regulation of imprinted DNA methylation. Cytogenet Genome Res., 113(1-4):122-9, 2006.

Ferguson-Smith A. C. Genomic imprinting: the emergence of an epigenetic paradigm. Nat. Rev. Genet., 12(8):565-75, 2011.

Li, E; Beard C. and Jaenisch R. Role for DNA methylation in genomic imprinting. Nature 366, (6453): 362-5, 1993.

$\mathrm{Li}$, E. Chromatin modification and epigenetic reprogramming in mammalian development. Nat. Rev. Genet., 3(9):662-73, 2002.

Lu, Y.; Wang, F.; Li, Y.; Ferris, J.; Lee, J.A.; Gao F.B. The Drosophila homologue of the Angelman syndrome ubiquitin ligase regulates the formation of terminal dendritic branches. Hum. Mol. Genet., 18(3):454-62, 2009.
Reik, W. ; Dean, W. ; Walter J. Epigenetic Reprogramming in Mammalian Development. Science, 293:1089-93, 2001.

Sha, K. A mechanistic view of genomic imprinting. Annu. Rev. Genomics Human Genet., 9:197-216, 2008.

Weaver, J. R.; Susiarjo, M.; Bartolomei, M. S. Imprinting and epigenetic changes in the early embryo. Mamm. genome 20:532-43, 2009.

Weinstein, L. S. The role of tissue-specific imprinting as a source of phenotypic heterogeneity in human disease. Biol. Psychiatry, 50(12):927-31, 2001.

Wilkinson, L. S.; William D. and Anthony R. I. Genomic imprinting effects on brain development and function. Nat. Rev. Neurosc., 8(11): 832-43, 2007.

\section{Dirección para correspondencia:}

Miguel Concha

Laboratorio de Estudios Ontogénicos

Programa de Anatomía y Biología del Desarrollo

Facultad de Medicina, Universidad de Chile.

Independencia 1027

Santiago - CHILE

Email:mconcha@med.uchile.cl

Recibido : 25-07-2012

Aceptado: 19-08-2012 